\title{
Plasma levels of hypoxia-regulated factors in patients with age-related macular degeneration
}

\author{
Zygoula loanna $^{1} \cdot$ Schori Christian $^{2} \cdot$ Grimm $^{\text {Christian }}{ }^{2} \cdot$ Barthelmes Daniel $^{1}$ (I)
}

Received: 28 June 2017 / Revised: 18 September 2017 / Accepted: 4 November 2017 / Published online: 25 November 2017

(C) The Author(s) 2017. This article is an open access publication

\begin{abstract}
Purpose Various hypoxia-related proteins are differentially expressed in the retina and secreted to the vitreous and/or aqueous humor of patients affected by dry or neovascular age-related macular degeneration (nAMD). To determine whether these conditions alter concentrations of cytokines also in the systemic circulation, we measured plasma levels of six hypoxia-related proteins.

Methods Plasma was prepared from EDTA blood that was collected from patients affected by dry AMD $(n=5), \mathrm{nAMD}(n=11)$, proliferative diabetic retinopathy (PDR; $n=9$ ), and patients with an epiretinal membrane (ERM; $n=11)$. ERM samples served as negative controls, PDR samples as positive controls. Protein concentrations of vascular endothelial growth factor (VEGF), erythropoietin (EPO), angiopoietin-like 4 (ANGPTL4), placental growth factor (PlGF), tumor necrosis factor alpha (TNF- $\alpha$ ), and pigment epithelium-derived factor (PEDF) were determined by enzyme-linked immunosorbent assay (ELISA).

Results The concentration of PlGF was significantly increased in plasma of patients affected by nAMD. Although no statistically significant differences were found for EPO, ANGPTL4, PIGF, TNF- $\alpha$, and PEDF, the mean concentration of VEGF was lowest in the nAMD group. Plasma concentrations of the six factors did not correlate with gender or age of patients.

Conclusions nAMD may increase plasma concentrations of PlGF, making it a candidate as a biomarker for the neovascular form of AMD. Other factors, however, were not differentially regulated, suggesting that their systemic concentrations are not generally increased in hypoxia-related retinal diseases.
\end{abstract}

Keywords Age-related macular degeneration $\cdot$ Vascular endothelial growth factor $\cdot$ Cytokines $\cdot$ Plasma

\section{Introduction}

Age-related macular degeneration (AMD) is a leading cause of irreversible and progressive vision loss among the elderly in the Western world [1-3]. While deterioration of vision in dry AMD (geographic atrophy) occurs slowly, vision loss in neovascular AMD (nAMD) often happens within a few months $[4,5]$. The severity and socio-economic impact of

Zygoula Ioanna and Schori Christian has Equal contribution, shared first authorship

Barthelmes Daniel

dbar8165@uni.sydney.edu.au

1 Department of Ophthalmology, University Hospital Zurich, Frauenklinikstrasse 24, 8091 Zurich, Switzerland

2 Lab for Retinal Cell Biology, Department of Ophthalmology, Zurich Centre for Integrative Human Physiology (ZIHP), and Neuroscience Centre (ZNZ), University of Zurich, Zurich, Switzerland
AMD combined with its increasing incidence makes an efficient treatment an urgent medical need. Several compounds that target vascular endothelial growth factor (VEGF) have been developed that demonstrate unprecedented results in randomized clinical trials preventing vision loss in the majority of patients with nAMD [6-9]. However, to date, no therapy has been approved for dry AMD.

Understanding the pathogenesis of dry AMD, i.e., the processes leading to the formation of geographic atrophy, is critical for the development of efficient therapies. Apart from known risk factors such as advanced age, cigarette smoke, high body mass index, and genetic variants [10-12], inflammation and oxidative damage have been implicated in disease induction and/or progression [13]. Recently, it was hypothesized that reduced tissue oxygenation (hypoxia) may be another contributing factor not only for the pathogenesis of nAMD but also of dry AMD [14, 15]. Reduced choroidal blood flow and tissue changes in the aging eye may reduce oxygen delivery to the retinal pigment epithelium (RPE) and the outer layer of the 
neuronal retina, potentially inducing mild but chronic hypoxia in photoreceptor cells and RPE. This may lead to the activation of hypoxia-inducible transcription factors (HIFs) $[16,17]$ and consequently to the induction of HIF target genes including VEGF [18, 19], a main factor for the development of choroidal neovascularization in nAMD [20-23]. In addition to VEGF, hypoxia increases expression of several additional factors such as angiopoietin like 4 (ANGPTL4), placental growth factor (PlGF), pigment epithelium derived factor (PEDF), tumor necrosis factor (TNF- $\alpha$ ), erythropoietin (EPO), and others that have been implicated in angiogenesis, neovascularization, and/or inflammation [24-29]. To address whether patients suffering from retinal disease with a hypoxic component also show systemic changes of these hypoxia-regulated proteins, we studied plasma samples from patients with nAMD, dry AMD and patients with proliferative diabetic retinopathy (PDR). The nonhypoxic control group comprised of samples from patients with epiretinal membranes (ERM).

\section{Materials and methods}

\section{Patients, collection of plasma, and ELISA}

This non-interventional, single-center study at the Department of Ophthalmology at the University Hospital Zurich enrolled 36 participants and was approved by the human ethics committee of the Canton of Zurich, Switzerland. All study subjects were recruited among patients who were regularly scheduled for cataract surgery or vitrectomy. Informed consent was obtained from all participants prior to participation. The study adheres to the tenets of the Declaration of Helsinki. All participants underwent ophthalmologic examination 1 day before and 1 day after surgery as well as follow-up examinations after 1 month. The blood samples were collected by venous puncture prior to surgery, i.e., at a time when no additional oxygenation or medication was administered. At the time of taking blood samples, patients had been fasting for at least $6 \mathrm{~h}$.

Exclusion criteria were: glaucoma, intraocular surgery within the last 6 months, ocular medications other than lubricants, intraocular inflammation, non-proliferative diabetic retinopathy, myopia of more than 6 diopters spherical equivalent, any other ocular vascular disease, previous retinal detachment, previous vitrectomy, retinal degenerative disease, and presence of any other retinal condition potentially affecting either function or oxygenation of the retina other than $\mathrm{AAMD}$, dry AMD, or proliferative diabetic retinopathy (PDR). Patients with PDR or nAMD who received anti-VEGF treatments must have had a minimum interval of 2 weeks between sample collection and last intravitreal injection of an anti-VEGF drug.

Patients were assessed clinically during routine clinics and underwent slit-lamp examination, visual acuity testing, measurement of intraocular pressure, and optical coherence imaging.

Patients with PDR are known to have a strong vascular response that involves activation of HIF transcription factors due to local hypoxia caused by reduced retinal perfusion and microvascular complications [30-35]. These samples served as a "positive control" for a hypoxic ocular response. All participants were ophthalmological patients referred to undergo intraocular surgery, thus we selected patients with ERM to serve as "negative control" because they are not known to have any hypoxia-related changes in the retina.

Based on available literature, we selected VEGF, EPO, ANGPTL4, PIGF, TNF- $\alpha$, and PEDF as hypoxia-related factors [24, 25, 27, 36-39] to be tested in plasma as follows: Blood was collected in EDTA tubes and kept on ice until use. Plasma was prepared by centrifugation of the EDTA blood at $1300 \times g$ for 15 min within $2 \mathrm{~h}$ after collection. Aliquots were prepared and stored in liquid nitrogen until analysis. Plasma concentrations of the six factors were determined by ELISA using the DuoSet (ANGPTL4 and PEDF) or the Quantikine format (VEGF, EPO, PlGF, TNF- $\alpha$ ) according to manufacturer's instructions ( $\mathrm{R} \& \mathrm{D}$ Systems Inc., Minneapolis, Minnesota, USA). The minimal detectable dose (MDD) was defined as the value received by addition of two standard deviations to the mean optical density value of zero standard measurements. For the different factors the MDD was as follows: VEGF: $9 \mathrm{pg} / \mathrm{ml}$; EPO: $6 \mathrm{mIU} / \mathrm{ml}$; PlGF: $0.14 \mathrm{pg} / \mathrm{ml}$; TNF- $\alpha$ : $0.12 \mathrm{pg} / \mathrm{ml}$; ANGPTL4: $0.79 \mathrm{ng} / \mathrm{ml}$; PEDF: $2.21 \mathrm{ng} / \mathrm{ml}$.

\section{Statistical analyses}

Quantification of ELISA data was done by GraphPad Prism version 6.0f for Mac OS X (GraphPad Software, La Jolla, CA, USA) using Sigmoidal 4PL fit with $1 / y^{2}$ correction for heteroscedasticity. Numbers were expressed as median (interquartile range (IQR)) Differences among groups were analyzed by one way analysis of variance (ANOVA), followed by Kruskal-Wallis rank sum test with Benjamini-Hochberg post-test for individual comparisons between groups. This statistical analysis was performed by $\mathrm{R}$ (Version 3.2.3) and $\mathrm{R}$ Studio (Version 0.99.887; R Core Team (2015), Vienna, Austria) with Ggplot2 (H. Wickham, 2009), dunn.test (A. Dinno, 2016) packages.

\section{Results}

\section{Patients/demographics}

Blood plasma samples were collected from 36 patients that were diagnosed with nAMD (11 patients), dry AMD (five patients) or PDR (nine patients). Eleven patients with an 
ERM served as controls. The mean age of all patients was 72 \pm 14 years. Detailed demographic data are shown below in Table 1.

All patients with nAMD received intravitreal injections of anti-VEGF drugs. Cataract surgeries were scheduled between two consecutive injections. Only three of the nine patients with PDR received intravitreal ranibizumab as only in those three a macular edema was diagnosed. All of the patients had undergone peripheral laser photocoagulation. Intraocular pressure was within normal ranges in all patient groups. Clinical information is detailed in Table 2.

\section{Plasma levels of hypoxia-related factors}

Nearly all measured values were in the normal range reported for the factors in human plasma [40-48]. Plasma levels of PlGF were significantly higher in $\mathrm{nAMD}$ patients than in all other patient groups (Fig. 1).

Although all other factors analyzed were statistically similarly expressed in all groups, VEGF showed a tendency towards lower levels in patients suffering from nAMD. As stated, all of these patients underwent intraocular anti-VEGF therapy 2-4 weeks before collection of plasma suggesting that the local treatment affected systemic VEGF levels. Mean levels of EPO were slightly elevated in patients of the nAMD and PDR groups (Fig. 1). Both nAMD and PDR have an established hypoxic component. Values outside IQR were from different patients, except for VEGF and EPO in the dry AMD group and PEDF and EPO in the ERM group. Notably, the two patients with VEGF values above average in the dry AMD group also had above-average levels for EPO, PEDF, and TNF. One of the two patients had also above-average levels of PlGF in addition. No correlation between plasma levels of the factors to sex or age of patients was found.

\section{Discussion}

The aim of our study was to evaluate whether plasma levels of hypoxia-related factors implicated in pathologic angiogenesis such as in nAMD, dry AMD, or PDR are significantly altered. To our knowledge, this is the first study simultaneously

Table 1 Patient groups and demographic data

\begin{tabular}{|c|c|c|c|c|}
\hline \multirow[t]{2}{*}{ Disease group } & \multirow[t]{2}{*}{ No. of patients } & \multirow{2}{*}{$\begin{array}{l}\text { Age (years); } \\
\text { mean } \pm \mathrm{SE}\end{array}$} & \multicolumn{2}{|c|}{ Gender } \\
\hline & & & Male & Female \\
\hline Dry AMD & 5 & $80 \pm 7$ & 1 & 4 \\
\hline nAMD & 11 & $80 \pm 5$ & 4 & 7 \\
\hline PDR & 9 & $59 \pm 2$ & 4 & 5 \\
\hline ERM & 11 & $71 \pm 4$ & 5 & 6 \\
\hline
\end{tabular}

comparing plasma levels of factors implicated in hypoxiarelated tissue responses in four different patient groups.

Although VEGF is considered to be the most important angiogenic factor for the development of retinal and choroidal neovascularization [49], additional factors such as EPO [50], ANGPTL4 [24], PIGF [51], and others may also contribute to disease development. TNF- $\alpha$ for example has been found in the ischemic retina [52], which implicates it in the response to hypoxia and in retinal angiogenesis, even though TNF- $\alpha$ has mostly been connected to inflammatory processes. PEDF is considered as an anti-angiogenic factor counteracting VEGF [53]. Misregulation in hypoxia may result in an imbalance between PEDF and VEGF potentially contributing to retinal neovascularization $[54,55]$. Here we show that only PlGF was significantly increased in the plasma of nAMD patients whereas levels of VEGF, EPO, PEDF, ANGPTL4, and TNF- $\alpha$ did not significantly vary across patient groups. Although it has been reported that PlGF contributes to choroidal neovascularization [25], PlGF has not yet been determined in the circulation of AMD patients. We found that the plasma concentration of PIGF was significantly elevated in nAMD and differed from the other patient groups, as shown in Fig. 1. However, only about $50 \%$ of the nAMD patients presented plasma levels that were above the median of the control group. Clearly, a more detailed investigation with an increased cohort size and a careful correlation of PlGF levels with the severity of disease, status of therapy and response efficacy to anti-VEGF treatment is needed to identify the reason for this variability. At this point, it should be mentioned that apart from angiogenesis, PlGF has been associated with other systemic diseases including atherosclerosis [56], hypertension [57], and coronary artery disease [58]. Similarly, cardiovascular disease and hypertension have also been associated with nAMD [59]. On the other hand, despite the fact of a relatively high prevalence of these diseases in the elderly, they are not exclusive for a particular eye condition; thus it is likely that these effects would be leveled out among the different patient groups. However, since the present study was conducted without taking into consideration any systemic diseases, a possible influence of any systemic disease on the plasma levels of the studied factors cannot be neglected. However, PlGF is an interesting and promising candidate for further studies.

The lowest median plasma concentration of VEGF was unexpectedly found in nAMD patients (Fig. 1) where high intraocular levels of VEGF are causative for the neovascularization that characterizes the disease. The low plasma levels of VEGF were possibly related to the anti-VEGF treatment that all nAMD patients had received 2-4 weeks prior to sample collection. It is interesting to note that median VEGF levels in the dry AMD group tended to be elevated when compared to controls, implying a potential contribution of VEGF and/or hypoxia to the development or progression of this disease. Although earlier reports show elevated VEGF levels in 
Table 2 Clinical data

\begin{tabular}{|c|c|c|c|c|c|}
\hline \multirow[t]{2}{*}{ Disease group } & \multicolumn{2}{|l|}{ Visual acuity } & \multirow[t]{2}{*}{ Intraocular pressure (mean) } & \multirow[t]{2}{*}{ Anti-VEGF therapy } & \multirow[t]{2}{*}{ Peripheral laser coagulation } \\
\hline & Min & Max & & & \\
\hline Dry AMD & $20 / 60$ & $20 / 40$ & $14 \mathrm{mmHg}$ & - & \\
\hline \multirow[t]{3}{*}{ nAMD } & Hand movements & $20 / 60$ & $14 \mathrm{mmHg}$ & 5/11 ranibizumab and aflibercept & \\
\hline & & & & $5 / 11$ ranibizumab only & \\
\hline & & & & $1 / 11$ aflibercept only & \\
\hline PDR & Counting fingers & $20 / 100$ & $15 \mathrm{mmHg}$ & $3 / 9$ ranibizumab only & $9 / 9$ \\
\hline ERM & $20 / 200$ & $20 / 30$ & $16 \mathrm{mmHg}$ & - & \\
\hline
\end{tabular}

plasma of PDR patients [60-62], VEGF was not above control in our PDR patient group (Fig. 1). All our PDR patients had received panretinal laser coagulation and three of them at least once an anti-VEGF therapy prior to surgery, potentially explaining this difference. Alternatively, the discrepancy may be based on the generally good control of blood sugar levels in Swiss diabetics [63]: it has been reported that plasma levels of VEGF were elevated in diabetics with poor blood sugar control but dropped to the normal range after patients had achieved better control [64]. In addition, the studies reporting higher VEGF levels were conducted in nonCaucasians $[60,65]$, which may point to potential differences between patient cohorts and/or ethnic groups.

The median plasma concentrations of ANGPTL4, TNF- $\alpha$, PEDF, and EPO were not statistically different from their respective controls. Nevertheless, some variations were apparent. Although not reaching significance, EPO was high in the nAMD and PDR group where increased levels have been reported before $[38,66]$. Both groups have a strong vascular phenotype as a result of hypoxic insults. As a classical hypoxia-regulated protein, increased EPO levels in these patients may thus reflect the hypoxic state of the ocular tissue that led to the vascular phenotype. This is also reflected in median levels of ANGPTL4, which are elevated in all groups compared to non-hypoxic controls (ERM). Elevated levels of ANGPTL4 in PDR in patients were already reported before and the factor is discussed as potential therapeutic target for patients suffering from diabetic retinopathy [24]. Elevated plasma levels of PEDF and TNF- $\alpha$ were demonstrated in PDR patients [67-69]. PEDF was also increased in nAMD when compared to dry AMD [70]. The authors also reported a positive correlation between VEGF and PEDF in the nAMD group. These data were not corroborated in our study.

Although significant changes in intraocular levels of the investigated factors have been reported for pathologies involving hypoxic conditions [71-76], most changes in the
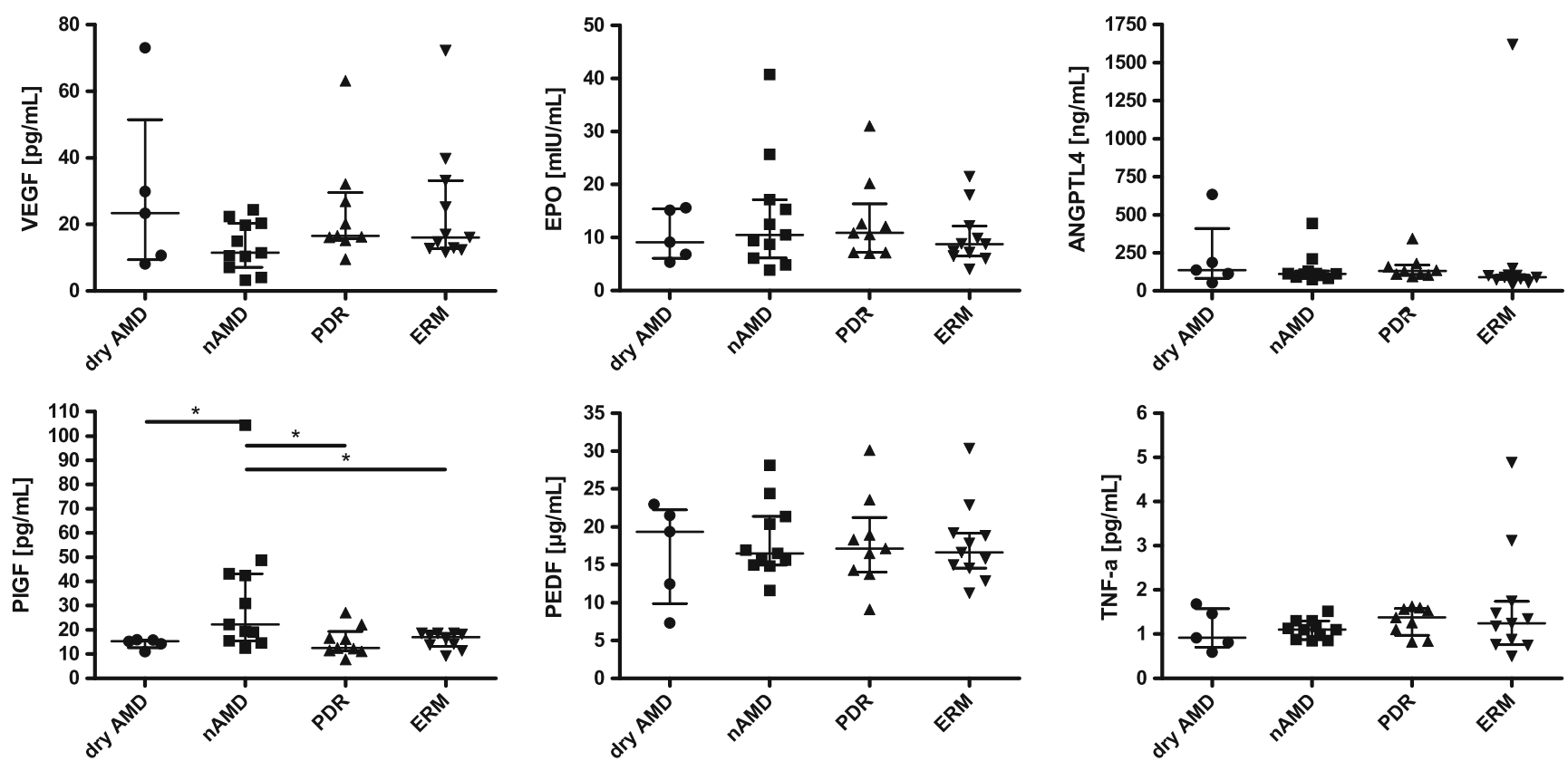

Fig. 1 Concentrations of factors in plasma of patients. Shown are individual data points, as well as median (IQR). $N=5$ (dry AMD), $N=11$ (nAMD), $N=9$ (PDR), $N=11$ (ERM). *: $P<0.05$ 
circulation of our patient groups were only minor, the exception being PlGF. Why only some of the hypoxia-regulated factors that were found to be increased in the eye were elevated in plasma of patients while others were not is unclear. Possible explanations may include different stabilities of the proteins in ocular fluids and plasma, differences in the cell types producing the factors, differential secretion, or others. Additionally, differences in patient care, e.g., variability in the control of blood sugar levels, potential differences between ethnic groups, and the size of the cohorts tested may influence data outcome and explain differences to published data. It seems likely, however, that ocular concentrations of specific factors in the diseased eye do not necessarily correlate with factor concentrations in plasma. Therefore, our data suggest that the response to hypoxic events in retinal pathologies remains mostly local, even though many factors produced by such conditions are secreted proteins. The confinement of hypoxia-induced angiogenic factors to the local environment of the eye might thus help to prevent potentially dangerous systemic neo-angiogenesis in patients. This possibility needs to be taken into consideration when searching for circulating biomarkers for eye pathologies.

\section{Strengths/limitations}

The strength of our study is that we used a protocol ensuring that all procedures were performed the same way in all patients. Furthermore, we studied and compared for the first time to our knowledge three different groups with the following retinal hypoxic diseases: nAMD, dry AMD, and PDR as well ERM as a non-hypoxic control group. This simultaneous analysis allows for a direct comparison of values measured.

However, the limitation of the study is that the number of the enrolled patients was very small and not equal for all groups, making it difficult to demonstrate comparability among the groups. Since only very few cytokine studies have been conducted so far, the availability of commercial kits was limited and their use needed some tweaking to work efficiently. Moreover, we restricted the exclusion criteria only to eye conditions without referring to any systemic diseases, which could also have an influence on plasma levels of the studied factors.

\section{Conclusions}

Based on the current results, we hypothesize that local intraocular regulatory mechanisms regarding cytokine secretion under hypoxic conditions exist $[50,66]$ that are unrelated to systemic regulation. Trends in the different cytokines such as elevated levels of ANGPTL4 in the dry AMD group suggest new avenues for therapeutic targets in dry AMD. Since our study included only a small number of patients, further studies with larger patient groups are needed to verify a possible systemic expression of factors related to hypoxia-induced angiogenesis in the eye.

Acknowledgements The authors thank Elena Lüssi and Sarah Steinmann for the administrative support and help in preparing the blood samples.

Funding Novartis Schweiz AG provided financial support in the form of a research agreement.

The sponsor had no role in the design or conduct of this research.

\section{Compliance with ethical standards}

Conflict of interest All authors certify that they have no affiliations with or involvement in any organization or entity with any financial interest (such as honoraria; educational grants; participation in speakers' bureaus; membership, employment, consultancies, stock ownership, or other equity interest; and expert testimony or patent-licensing arrangements), or non-financial interest (such as personal or professional relationships, affiliations, knowledge or beliefs) in the subject matter or materials discussed in this manuscript.

Ethical approval All procedures performed in studies involving human participants were in accordance with the ethical standards of the institutional and/or national research committee and with the 1964 Helsinki Declaration and its later amendments or comparable ethical standards.

Informed consent Informed consent was obtained from all individual participants included in the study.

\section{Financial disclosure None.}

Open Access This article is distributed under the terms of the Creative Commons Attribution 4.0 International License (http:// creativecommons.org/licenses/by/4.0/), which permits unrestricted use, distribution, and reproduction in any medium, provided you give appropriate credit to the original author(s) and the source, provide a link to the Creative Commons license, and indicate if changes were made.

\section{References}

1. Klein R, Klein BE, Linton KL (1992) Prevalence of age-related maculopathy. Beaver Dam Eye Study Ophthalmol 99:933-943

2. Mitchell P, Smith W, Attebo K, Wang JJ (1995) Prevalence of agerelated maculopathy in Australia. Blue Mountains Eye Study Ophthalmol 102:1450-1460

3. Vingerling JR, Dielemans I, Hofman A, Grobbee DE, Hijmering M, Kramer CF, de Jong PT (1995) The prevalence of age-related maculopathy in the Rotterdam study. Ophthalmology 102:205-210

4. Group MPS (1990) Krypton laser photocoagulation for neovascular lesions of age-related macular degeneration. Results of a randomized clinical trial. Macular photocoagulation study group. Arch Ophthalmol 108:816-824

5. (1993) Laser photocoagulation of subfoveal neovascular lesions of age-related macular degeneration. Updated findings from two clinical trials. Macular Photocoagulation Study Group. Arch Ophthalmol 111: 1200-1209

6. Brown DM, Kaiser PK, Michels M, Soubrane G, Heier JS, Kim RY, Sy JP, Schneider S (2006) Ranibizumab versus verteporfin for 
neovascular age-related macular degeneration. N Engl J Med 355: 1432-1444. https://doi.org/10.1056/NEJMoa062655

7. Rosenfeld PJ, Brown DM, Heier JS, Boyer DS, Kaiser PK, Chung CY, Kim RY (2006) Ranibizumab for neovascular age-related macular degeneration. N Engl J Med 355:1419-1431. https://doi.org/ 10.1056/NEJMoa054481

8. Heier JS, Antoszyk AN, Pavan PR, Leff SR, Rosenfeld PJ, Ciulla TA, Dreyer RF, Gentile RC, Sy JP, Hantsbarger G, Shams N (2006) Ranibizumab for treatment of neovascular age-related macular degeneration: a phase I/II multicenter, controlled, multidose study. Ophthalmology 113(633):e631-e634. https://doi.org/10.1016/j. ophtha.2005.10.052

9. Martin DF, Maguire MG, Ying GS, Grunwald JE, Fine SL, Jaffe GJ (2011) Ranibizumab and bevacizumab for neovascular age-related macular degeneration. N Engl J Med 364:1897-1908. https://doi. org/10.1056/NEJMoa1102673

10. Khan JC, Thurlby DA, Shahid H, Clayton DG, Yates JR, Bradley M, Moore AT, Bird AC (2006) Smoking and age related macular degeneration: the number of pack years of cigarette smoking is a major determinant of risk for both geographic atrophy and choroidal neovascularisation. Br J Ophthalmol 90:75-80. https://doi.org/ 10.1136/bjo.2005.073643

11. Seddon JM, Cote J, Davis N, Rosner B (2003) Progression of agerelated macular degeneration: association with body mass index, waist circumference, and waist-hip ratio. Arch Ophthalmol 121: 785-792. https://doi.org/10.1001/archopht.121.6.785

12. Haines JL, Hauser MA, Schmidt S, Scott WK, Olson LM, Gallins P, Spencer KL, Kwan SY, Noureddine M, Gilbert JR, SchnetzBoutaud N, Agarwal A, Postel EA, Pericak-Vance MA (2005) Complement factor $\mathrm{H}$ variant increases the risk of age-related macular degeneration. Science 308:419-421. https://doi.org/10.1126/ science. 1110359

13. Cao S, Ko A, Partanen M, Pakzad-Vaezi K, Merkur AB, Albiani DA, Kirker AW, Wang A, Cui JZ, Forooghian F, Matsubara JA (2013) Relationship between systemic cytokines and complement factor $\mathrm{H} \mathrm{Y} 402 \mathrm{H}$ polymorphism in patients with dry age-related macular degeneration. Am J Ophthalmol 156:1176-1183. https:// doi.org/10.1016/j.ajo.2013.08.003

14. DaCosta J (2013) Minocycline protects retinal pigment epithelial cells from hypoxia. ARVO Meeting Abstr 54:4108

15. McLeod DS, Grebe R, Bhutto I, Merges C, Baba T, Lutty GA (2009) Relationship between RPE and Choriocapillaris in agerelated macular degeneration. Invest Ophthalmol Vis Sci 50: 4982-4991. https://doi.org/10.1167/Iovs.09-3639

16. Wang GL, Jiang BH, Rue EA, Semenza GL (1995) Hypoxiainducible factor 1 is a basic-helix-loop-helix-PAS heterodimer regulated by cellular O2 tension. Proc Natl Acad Sci U S A 92: $5510-5514$

17. Wang GL, Semenza GL (1993) General involvement of hypoxiainducible factor 1 in transcriptional response to hypoxia. Proc Natl Acad Sci U S A 90:4304-4308

18. Vadlapatla RK, Vadlapudi AD, Pal D, Mukherji M, Mitra A (2013) Ritonavir inhibits HIF-1 \{alpha\} mediated VEGF expression in retinal pigment epithelial cells. ARVO Meeting Abstr 54:3275

19. Ozaki H, Yu AY, Della N, Ozaki K, Luna JD, Yamada H, Hackett SF, Okamoto N, Zack DJ, Semenza GL, Campochiaro PA (1999) Hypoxia inducible factor-1alpha is increased in ischemic retina: temporal and spatial correlation with VEGF expression. Invest Ophthalmol Vis Sci 40:182-189

20. Kliffen M, Sharma HS, Mooy CM, Kerkvliet S, de Jong PT (1997) Increased expression of angiogenic growth factors in age-related maculopathy. Br J Ophthalmol 81:154-162

21. Lopez PF, Sippy BD, Lambert HM, Thach AB, Hinton DR (1996) Transdifferentiated retinal pigment epithelial cells are immunoreactive for vascular endothelial growth factor in surgically excised age- related macular degeneration-related choroidal neovascular membranes. Invest Ophthalmol Vis Sci 37:855-868

22. Tong JP, Chan WM, Liu DT, Lai TY, Choy KW, Pang CP, Lam DS (2006) Aqueous humor levels of vascular endothelial growth factor and pigment epithelium-derived factor in polypoidal choroidal vasculopathy and choroidal neovascularization. Am J Ophthalmol 141: 456-462. https://doi.org/10.1016/j.ajo.2005.10.012

23. Wang F, Rendahl KG, Manning WC, Quiroz D, Coyne M, Miller SS (2003) AAV-mediated expression of vascular endothelial growth factor induces choroidal neovascularization in rat. Invest Ophthalmol Vis Sci 44:781-790

24. Babapoor-Farrokhran S, Jee K, Puchner B, Hassan SJ, Xin X, Rodrigues M, Kashiwabuchi F, Ma T, Hu K, Deshpande M, Daoud Y, Solomon S, Wenick A, Lutty GA, Semenza GL, Montaner S, Sodhi A (2015) Angiopoietin-like 4 is a potent angiogenic factor and a novel therapeutic target for patients with proliferative diabetic retinopathy. Proc Natl Acad Sci U S A 112:E3030 E3039. https://doi.org/10.1073/pnas.1423765112

25. Rakic JM, Lambert V, Devy L, Luttun A, Carmeliet P, Claes C, Nguyen L, Foidart JM, Noel A, Munaut C (2003) Placental growth factor, a member of the VEGF family, contributes to the development of choroidal neovascularization. Invest Ophthalmol Vis Sci 44:3186-3193

26. He X, Cheng R, Benyajati S, Ma JX (2015) PEDF and its roles in physiological and pathological conditions: implication in diabetic and hypoxia-induced angiogenic diseases. Clin Sci (Lond) 128: 805-823. https://doi.org/10.1042/CS20130463

27. Li S, Fu XA, Zhou XF, Chen YY, Chen WQ (2012) Angiogenesisrelated cytokines in serum of proliferative diabetic retinopathy patients before and after vitrectomy. Int J Ophthalmol 5:726-730. https://doi.org/10.3980/j.issn.2222-3959.2012.06.14

28. Zhou J, Wang S, Xia X (2012) Role of intravitreal inflammatory cytokines and angiogenic factors in proliferative diabetic retinopathy. Curr Eye Res 37:416-420. https://doi.org/10.3109/02713683. 2012.661114

29. Mirshahi A, Hoehn R, Lorenz K, Kramann C, Baatz H (2012) Antitumor necrosis factor alpha for retinal diseases: current knowledge and future concepts. J Ophthalmic Vis Res 7:39-44

30. Lim JI, Spee C, Hinton DR (2010) A comparison of hypoxiainducible factor-alpha in surgically excised neovascular membranes of patients with diabetes compared with idiopathic epiretinal membranes in nondiabetic patients. Retina 30:1472-1478. https://doi. org/10.1097/IAE.0b013e3181d6df09

31. Stitt AW, Gardiner TA, Archer DB (1995) Histological and ultrastructural investigation of retinal microaneurysm development in diabetic patients. Br J Ophthalmol 79:362-367

32. Boeri D, Maiello M, Lorenzi M (2001) Increased prevalence of microthromboses in retinal capillaries of diabetic individuals. Diabetes 50:1432-1439

33. Joussen AM, Murata T, Tsujikawa A, Kirchhof B, Bursell SE, Adamis AP (2001) Leukocyte-mediated endothelial cell injury and death in the diabetic retina. Am J Pathol 158:147-152. https://doi.org/10.1016/S0002-9440(10)63952-1

34. Jiang F, Tang YT, Guo L, Jiao XY (2013) The role of insulin-like growth factor I and hypoxia inducible factor 1alpha in vascular endothelial growth factor expression in type 2 diabetes. Ann Clin Lab Sci 43:37-44

35. Wang X, Wang G, Wang Y (2009) Intravitreous vascular endothelial growth factor and hypoxia-inducible factor 1a in patients with proliferative diabetic retinopathy. Am J Ophthalmol 148:883-889. https://doi.org/10.1016/j.ajo.2009.07.007

36. Zehetner C, Kirchmair R, Kralinger M, Kieselbach G (2013) Correlation of vascular endothelial growth factor plasma levels and glycemic control in patients with diabetic retinopathy. Acta Ophthalmol 91:e470-e473. https://doi.org/10.1111/aos.12081 
37. Lip PL, Chatterjee S, Caine GJ, Hope-Ross M, Gibson J, Blann AD, Lip GY (2004) Plasma vascular endothelial growth factor, angiopoietin-2, and soluble angiopoietin receptor tie-2 in diabetic retinopathy: effects of laser photocoagulation and angiotensin receptor blockade. Br J Ophthalmol 88:1543-1546. https://doi.org/ 10.1136/bjo.2004.048587

38. Gholamhossein Y, Behrouz H, Asghar Z (2014) Diabetic retinopathy risk factors: plasma erythropoietin as a risk factor for proliferative diabetic retinopathy. Korean J Ophthalmol 28:373-378. https:// doi.org/10.3341/kjo.2014.28.5.373

39. Dawson DW, Volpert OV, Gillis P, Crawford SE, Xu H, Benedict W, Bouck NP (1999) Pigment epithelium-derived factor: a potent inhibitor of angiogenesis. Science 285:245-248

40. Larsson A, Skoldenberg E, Ericson H (2002) Serum and plasma levels of FGF-2 and VEGF in healthy blood donors. Angiogenesis 5:107-110

41. Wognum AW, Lam V, Goudsmit R, Krystal G (1990) A specific in vitro bioassay for measuring erythropoietin levels in human serum and plasma. Blood 76:1323-1329

42. Bruno CM, Neri S, Sciacca C, Bertino G, Di Prima P, Cilio D, Pellicano R, Caruso L, Cristaldi R (2004) Plasma erythropoietin levels in anaemic and non-anaemic patients with chronic liver diseases. World J Gastroenterol 10:1353-1356

43. Jonker JT, Smit JW, Hammer S, Snel M, van der Meer RW, Lamb HJ, Mattijssen F, Mudde K, Jazet IM, Dekkers OM, de Roos A, Romijn JA, Kersten S, Rensen PC (2013) Dietary modulation of plasma angiopoietin-like protein 4 concentrations in healthy volunteers and in patients with type 2 diabetes. Am J Clin Nutr 97:255260. https://doi.org/10.3945/ajcn.112.043687

44. Jeevaratnam K, Nadarajah VD, Judson JP, Nalliah S, Abdullah MF (2010) Periodic assessment of plasma sFlt-1 and PlGF concentrations and its association with placental morphometry in gestational hypertension $(\mathrm{GH})$ - a prospective follow-up study. BMC Pregnancy Childbirth 10:58. https://doi.org/10.1186/1471-2393$10-58$

45. Krauss T, Pauer HU, Augustin HG (2004) Prospective analysis of placenta growth factor (PlGF) concentrations in the plasma of women with normal pregnancy and pregnancies complicated by preeclampsia. Hypertens Pregnancy 23:101-111. https://doi.org/ 10.1081/PRG-120028286

46. Himmerich H, Fulda S, Linseisen J, Seiler H, Wolfram G, Himmerich S, Gedrich K, Pollmacher T (2006) TNF-alpha, soluble TNF receptor and interleukin- 6 plasma levels in the general population. Eur Cytokine Netw 17:196-201

47. Petersen SV, Valnickova Z, Enghild JJ (2003) Pigment-epitheliumderived factor (PEDF) occurs at a physiologically relevant concentration in human blood: purification and characterization. Biochem J 374:199-206. https://doi.org/10.1042/BJ20030313

48. Li X, Wang T, Yang T, Shen Y, An J, Liu L, Dong J, Guo L, Li D, Zhang X, Chen L, Xu D, Wen F (2015) Elevated plasma levels of pigment epithelium-derived factor correlated with inflammation and lung function in COPD patients. Int J Chron Obstruct Pulmon Dis 10:587-594. https://doi.org/10.2147/COPD.S78546

49. Witmer AN, Vrensen GF, Van Noorden CJ, Schlingemann RO (2003) Vascular endothelial growth factors and angiogenesis in eye disease. Prog Retin Eye Res 22:1-29

50. Watanabe D, Suzuma K, Matsui S, Kurimoto M, Kiryu J, Kita M, Suzuma I, Ohashi H, Ojima T, Murakami T, Kobayashi T, Masuda S, Nagao M, Yoshimura N, Takagi H (2005) Erythropoietin as a retinal angiogenic factor in proliferative diabetic retinopathy. N Engl J Med 353:782-792. https://doi. org/10.1056/NEJMoa041773

51. Yao YG, Yang HS, Cao Z, Danielsson J, Duh EJ (2005) Upregulation of placental growth factor by vascular endothelial growth factor via a post-transcriptional mechanism. FEBS Lett 579:1227-1234. https://doi.org/10.1016/j.febslet.2005.01.017
52. Zheng L, Gong B, Hatala DA, Kern TS (2007) Retinal ischemia and reperfusion causes capillary degeneration: similarities to diabetes. Invest Ophthalmol Vis Sci 48:361-367. https://doi.org/10. 1167/iovs.06-0510

53. Zhang SX, Wang JJ, Gao G, Parke K, Ma JX (2006) Pigment epithelium-derived factor downregulates vascular endothelial growth factor (VEGF) expression and inhibits VEGF-VEGF receptor 2 binding in diabetic retinopathy. J Mol Endocrinol 37:1-12. https://doi.org/10.1677/jme.1.02008

54. Gao G, Li Y, Zhang D, Gee S, Crosson C, Ma J (2001) Unbalanced expression of VEGF and PEDF in ischemia-induced retinal neovascularization. FEBS Lett 489:270-276

55. Ogata N, Nishikawa M, Nishimura T, Mitsuma $Y$, Matsumura $M$ (2002) Unbalanced vitreous levels of pigment epithelium-derived factor and vascular endothelial growth factor in diabetic retinopathy. Am J Ophthalmol 134:348-353

56. Khurana R, Moons L, Shafi S, Luttun A, Collen D, Martin JF, Carmeliet P, Zachary IC (2005) Placental growth factor promotes atherosclerotic intimal thickening and macrophage accumulation. Circulation 111:2828-2836. https://doi.org/10.1161/ CIRCULATIONAHA.104.495887

57. Carnevale D, Lembo G (2015) PlGF, immune system and hypertension. Oncotarget 6:18246-18247. 10.18632/oncotarget.4914

58. Fong SW, Few LL, See Too WC, Khoo BY, Nik Ibrahim NN, Yahaya SA, Yusof Z, Mohd Ali R, Abdul Rahman AR, YvonneTee GB (2015) Systemic and coronary levels of CRP, MPO, sCD40L and PlGF in patients with coronary artery disease. BMC Res Notes 8:679. https://doi.org/10.1186/s13104-015-1677-8

59. Hogg RE, Woodside JV, Gilchrist SE, Graydon R, Fletcher AE, Chan W, Knox A, Cartmill B, Chakravarthy U (2008) Cardiovascular disease and hypertension are strong risk factors for choroidal neovascularization. Ophthalmology 115:1046-1052 e1042. https://doi.org/10.1016/j.ophtha.2007.07.031

60. Ma Y, Zhang Y, Zhao T, Jiang YR (2012) Vascular endothelial growth factor in plasma and vitreous fluid of patients with proliferative diabetic retinopathy patients after intravitreal injection of bevacizumab. Am J Ophthalmol 153:307-313 e302. https://doi. org/10.1016/j.ajo.2011.08.006

61. Lip PL, Belgore F, Blann AD, Hope-Ross MW, Gibson JM, Lip GY (2000) Plasma VEGF and soluble VEGF receptor FLT-1 in proliferative retinopathy: relationship to endothelial dysfunction and laser treatment. Invest Ophthalmol Vis Sci 41:2115-2119

62. Wang J, Chen S, Jiang F, You C, Mao C, Yu J, Han J, Zhang Z, Yan $\mathrm{H}$ (2014) Vitreous and plasma VEGF levels as predictive factors in the progression of proliferative diabetic retinopathy after vitrectomy. PLoS One 9:e110531. https://doi.org/10.1371/journal.pone. 0110531

63. Kaiser A, Vollenweider P, Waeber G, Marques-Vidal P (2012) Prevalence, awareness and treatment of type 2 diabetes mellitus in Switzerland: the CoLaus study. Diabet Med 29:190-197. https:// doi.org/10.1111/j.1464-5491.2011.03422.x

64. Kakizawa $\mathrm{H}$, Itoh $\mathrm{M}$, Itoh $\mathrm{Y}$, Imamura $\mathrm{S}$, Ishiwata $\mathrm{Y}$, Matsumoto $\mathrm{T}$, Yamamoto K, Kato T, Ono Y, Nagata M, Hayakawa N, Suzuki A, Goto Y, Oda N (2004) The relationship between glycemic control and plasma vascular endothelial growth factor and endothelin-1 concentration in diabetic patients. Metabolism 53:550-555

65. Tsai DC, Charng MJ, Lee FL, Hsu WM, Chen SJ (2006) Different plasma levels of vascular endothelial growth factor and nitric oxide between patients with choroidal and retinal neovascularization. Ophthalmologica 220:246-251. https://doi.org/10.1159/ 000093079

66. Mohan N, Monickaraj F, Balasubramanyam M, Rema M, Mohan V (2012) Imbalanced levels of angiogenic and angiostatic factors in vitreous, plasma and postmortem retinal tissue of patients with proliferative diabetic retinopathy. J Diabetes Complicat 26:435-441. https://doi.org/10.1016/j.jdiacomp.2012.05.005 
67. Ogata N, Matsuoka M, Matsuyama K, Shima C, Tajika A, Nishiyama T, Wada M, Jo N, Higuchi A, Minamino K, Matsunaga H, Takeda T, Matsumura M (2007) Plasma concentration of pigment epithelium-derived factor in patients with diabetic retinopathy. J Clin Endocrinol Metab 92:1176-1179. https://doi. org/10.1210/jc.2006-2249

68. Doganay S, Evereklioglu C, Er H, Turkoz Y, Sevinc A, Mehmet N, Savli H (2002) Comparison of serum NO, TNF-alpha, IL-1beta, sIL-2R, IL-6 and IL-8 levels with grades of retinopathy in patients with diabetes mellitus. Eye (Lond) 16:163-170. https://doi.org/10. 1038/sj/EYE/6700095

69. Demircan N, Safran BG, Soylu M, Ozcan AA, Sizmaz S (2006) Determination of vitreous interleukin-1 (IL-1) and tumour necrosis factor (TNF) levels in proliferative diabetic retinopathy. Eye (Lond) 20:1366-1369. https://doi.org/10.1038/sj.eye.6702138

70. Machalinska A, Safranow K, Mozolewska-Piotrowska K, Dziedziejko V, Karczewicz D (2012) PEDF and VEGF plasma level alterations in patients with dry form of age-related degeneration-a possible link to the development of the disease. Klin Ocz 114:115-120

71. Aiello LP, Northrup JM, Keyt BA, Takagi H, Iwamoto MA (1995) Hypoxic regulation of vascular endothelial growth factor in retinal cells. Arch Ophthalmol 113:1538-1544

72. Grimm C, Wenzel A, Groszer M, Mayser H, Seeliger M, Samardzija M, Bauer C, Gassmann M, Reme CE (2002) HIF-1- induced erythropoietin in the hypoxic retina protects against lightinduced retinal degeneration. Nat Med 8:718-724. https://doi.org/ $10.1038 / \mathrm{nm} 723$

73. Xin X, Rodrigues M, Umapathi M, Kashiwabuchi F, Ma T, Babapoor-Farrokhran S, Wang S, Hu J, Bhutto I, Welsbie DS, Duh EJ, Handa JT, Eberhart CG, Lutty G, Semenza GL, Montaner S, Sodhi A (2013) Hypoxic retinal Muller cells promote vascular permeability by HIF-1-dependent up-regulation of angiopoietin-like 4. Proc Natl Acad Sci U S A 110:E3425E3434. https://doi.org/10.1073/pnas.1217091110

74. Tudisco L, Della Ragione F, Tarallo V, Apicella I, D'Esposito M, Matarazzo MR, De Falco S (2014) Epigenetic control of hypoxia inducible factor-1alpha-dependent expression of placental growth factor in hypoxic conditions. Epigenetics 9:600-610. https://doi. org/10.4161/epi.27835

75. Hempel SL, Monick MM, Hunninghake GW (1996) Effect of hypoxia on release of IL-1 and TNF by human alveolar macrophages. Am J Respir Cell Mol Biol 14:170-176. https://doi.org/10.1165/ ajrcmb.14.2.8630267

76. Yang XM, Yafai Y, Wiedemann P, Kuhrt H, Wang YS, Reichenbach A, Eichler W (2012) Hypoxia-induced upregulation of pigment epithelium-derived factor by retinal glial (Muller) cells. J Neurosci Res 90:257-266. https://doi.org/10.1002/jnr.22732 